\title{
Mechanical Performance of SiC based MEMS Capacitive Microphone for Ultrasonic Detection in Harsh Environment
}

\author{
S.A. Zawawi ${ }^{\mathrm{a}, \mathrm{c}}$, A.A. Hamzah ${ }^{* a}$, F. Mohd-Yasin ${ }^{\mathrm{b}}$ and B.Y. Majlis ${ }^{\mathrm{a}}$ \\ ${ }^{a}$ Institute of Microengineering and Nanoelectronics (IMEN), Universiti Kebangsaan Malaysia, \\ Bangi, 43600, Selangor, Malaysia; ${ }^{b}$ Queensland Micro- and Nanotechnology Centre, Griffith \\ University, Nathan, 4111, Queensland, Australia; ${ }^{\circ}$ UiTM Foundation Centre,Universiti Teknologi \\ Mara, Campus Dengkil, 43800 Dengkil, Selangor, Malaysia
}

\begin{abstract}
In this project, $\mathrm{SiC}$ based MEMS capacitive microphone was developed for detecting leaked gas in extremely harsh environment such as coal mines and petroleum processing plants via ultrasonic detection. The MEMS capacitive microphone consists of two parallel plates; top plate (movable diaphragm) and bottom (fixed) plate, which separated by an air gap. While, the vent holes were fabricated on the back plate to release trapped air and reduce damping. In order to withstand high temperature and pressure, a $1.0 \mu \mathrm{m}$ thick SiC diaphragm was utilized as the top membrane. The developed $\mathrm{SiC}$ could withstand a temperature up to $1400^{\circ} \mathrm{C}$. Moreover, the $3 \mu \mathrm{m}$ air gap is invented between the top membrane and the bottom plate via wafer bonding. COMSOL Multiphysics simulation software was used for design optimization. Various diaphragms with sizes of $600 \mu \mathrm{m}^{2}, 700 \mu \mathrm{m}^{2}, 800 \mu \mathrm{m}^{2}, 900 \mu \mathrm{m}^{2}$ and $1000 \mu \mathrm{m}^{2}$ are loaded with external pressure. From this analysis, it was observed that $\mathrm{SiC}$ microphone with diaphragm width of $1000 \mu^{2}$ produced optimal surface vibrations, with first-mode resonant frequency of approximately $36 \mathrm{kHz}$. The maximum deflection value at resonant frequency is less than the air gap thickness of $8 \mu \mathrm{m}$, thus eliminating the possibility of shortage between plates during operation. As summary, the designed $\mathrm{SiC}$ capacitive microphone has high potential and it is suitable to be applied in ultrasonic gas leaking detection in harsh environment.
\end{abstract}

Keywords: Silicon carbide, MEMS capacitive microphone, ultrasonic detection.

\section{INTRODUCTION}

Currently, the MicroElectro Mechanical System (MEMS) microphone converting acoustical input to electrical output has large market potential in electronics component, actuator and sensor devices. The low cost and high yield of MEMS microphone can be fabricated using combination of surface and bulk micromachining techniques [1,2]. Basically, MEMS microphones are widely applied in mobile devices [3], aeroacoustic measurement [4], hearing aid [5-9], and biomedical devices [10]. One of the most successfully-developed MEMS sensors is capacitive microphone consisting of thin and movable diaphragm separated by air gap with rigid perforated backplate. The desired design of this MEMS capacitive microphone is smaller in size and able to perform at high mechanical sensitivity [11]. Unfortunately, the size consideration limits the microphone performance in terms of frequency response and sensitivity [12].

As been reported by Torkkeli et al.,[13] the movable diaphragm greatly affect the mechanical performance of microphone devices and the types of diaphragm material also plays an important role as an in-plane stress. This is due to the dissimilar mechanical properties of each material which resulted in different mechanical sensitivity of the diaphragm. Bahram et al., [14] reported the similar issue about the material properties such as Young Modulus and Poison ratio which determines the mechanical sensitivity of the diaphragm performance.

Nanoengineering: Fabrication, Properties, Optics, and Devices XIV, edited by Eva M. Campo, Elizabeth A. Dobisz, Louay A. Eldada, Proc. of SPIE Vol. 10354, $103541 \mathrm{~J} \cdot$ (c) 2017 SPIE · CCC code: 0277-786X/17/\$18 - doi: 10.1117/12.2273717 
Various diaphragm materials that have been used such as silicon nitride [15-18] silicon [19-21], polysilicon [22-24], aluminum [25-27] and polyimide [28]. However, the listed materials have their drawback such as the deformable silicon diaphragm due to the high processing process [29] and suffer from low sensitivity [5] and aluminum that require a pullin voltage of $105 \mathrm{~V}$ because of the high stiffness of the Al diaphragm [14]. In harsh environment application, silicon exhibit several limitation such as operating temperature and radiation limit because of its properties [30]

Silicon carbide ( $\mathrm{SiC}$ ) material has several advantages over other material; it has superior mechanical properties in terms of density, thermal conductivity and Young's modulus. The quantitative comparison can be found in Table 1 of [31]. Other than that, the $\mathrm{SiC}$ is also superior over Si chemically in term of chemical inertness and corrosion resistance. The in-plane stress of $\mathrm{SiC}$ is found to be tensile with the maximum value of $1500 \mathrm{MPa}$. The main application of the $\mathrm{SiC}$ diaphragm will be as sensitive sensors applied in extreme environments. The material properties of SiC is summarized in Table I. The main objective of this paper is to investigate the superiority of employing SiC as diaphragm material of a capacitive microphone for sonic detection through a series of simulation.

Table 1. Material properties of $\mathrm{SiC}$.

\begin{tabular}{|l|l|}
\hline Material properties & $\mathrm{SiC}$ \\
\hline Young's modulus, $(\mathrm{GPa})$ & 4.70 \\
\hline Poisson's ratio & 0.22 \\
\hline Density $\left(\mathrm{kg} / \mu^{-3}\right)$ & $3.2 \times 10^{-15}$ \\
\hline Thermal conductivity $(\mathrm{pW} / \mu \mathrm{mK})$ & $5.0 \times 10^{8}$ \\
\hline Specific heat $(\mathrm{PJ} / \mathrm{kgK})$ & $1.34 \times 10^{15}$ \\
\hline
\end{tabular}

\section{THEORY}

\subsection{Maximum deflection and stress analysis of square diaphragm.}

The maximum deflection, $w$ of square diaphragm is measured at the center of the diaphragm due to uniform applied pressure, $p$ on its surface. The deflection of the diaphragm greatly depends on the material's properties such as Young's Modulus, Poisson's ratio and prestress [32]. The general equation for deflection of the diaphragm can be derived by analyzing the balance conditions between forces and bending moments for each side area of diaphragm, $d x d y$, as given by the following differential equation 1 and 2 [31]:

$$
D=\left[\frac{\partial^{4} w}{\partial x^{4}}+2 \frac{\partial^{4} w}{\partial x^{2} \partial y^{2}}+\frac{\partial^{4} w}{\partial y^{4}}\right]=p
$$

where $\mathrm{D}$ is flexural rigidity given by:

$$
D=\frac{E \cdot h^{3}}{12\left(1-v^{2}\right)}
$$

where $E, v$ and $h$ are Young's Modulus, Poisson's Ratio and diaphragm's thickness respectively.

Various approximate equations are presented to describe the pressure-deflection for a square diaphragm with a side length of $2 \mathrm{a}$ as shown in Figure 1. Considering the square diaphragm with small-deflection theory, the diaphragm deflect is small enough compare to the thickness of the diaphragm due to uniform applied pressure $(w / h<1 / 10)$. Then, the simplest relation between the pressure-deflection with small deflection for square diaphragm can be express by equation 3 [33]:

$$
P=3.41 \frac{\sigma_{o} h^{2}}{a^{2}}\left(\frac{w}{h}\right)+4.13 \frac{E h^{4}}{a^{4}\left(1-v^{2}\right)}\left(\frac{w}{h}\right)
$$


where $\sigma_{o}$ and $a$ are residual stress and half of side length of diaphragm respectively.

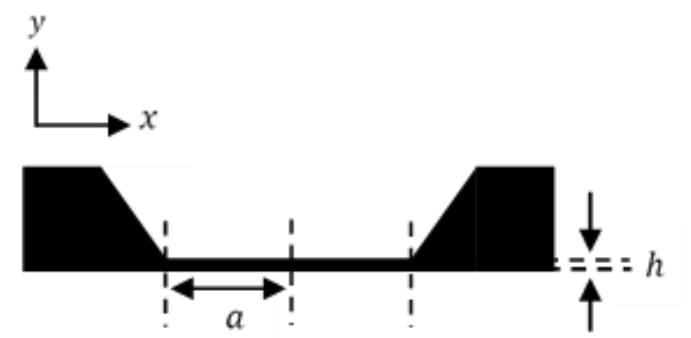

Figure 1. Schematic cross section of a square diaphragm.

As above-mentioned equation, the maximum deflection mainly affected by properties of diaphragm's material, dimension of diaphragm and residual stress. In addition, the maximum deflection increase linearly with driving voltage and influenced by diaphragm's thickness [33]. The residual stress should be included in order to determine the maximum total stress for small deflection condition [35]. Meanwhile the strain at the center of the deflection can be neglected as the maximum deflection is higher compare to the diaphragm's thickness [31].

Thus, only the maximum stress which is perpendicular to the edge is considered in this study. Therefore, the relationship of the maximum total stress, $\sigma_{\text {total }}$ and pressure, $p$ for square diaphragm can be calculated as following equation 4 [35]:

$$
\sigma_{\text {total }}=1.76 \frac{E h^{2}}{a^{2}}\left(\frac{w}{h}\right)
$$

\subsection{Design of condenser microphone}

A structural model for capacitive microphone consists of a parallel-plates, which is separated by an air gap as shown in Figure 2. The first is the top moveable diaphragm, made of back-etched $\mathrm{SiC}$ thin film. The second is a fixed bottom plate (or commonly referred as back plate) is made of $\mathrm{Si}$ wafer which contains acoustic holes (and herein referred as perforated plate) to reduce acoustic damping. Anodic bonding is used to join the $\mathrm{SiC}$ and $\mathrm{Si}$ wafers together. The $\mathrm{SiC}$ film undergo stress-deformation when an external pressure contacting its top surface. The change of the distance between these two plates is transduced into the differential capacitance value that being measured at the contact pads of both plates as the electrical output. While, the parameters used for this simulation are summarized in Table 2.

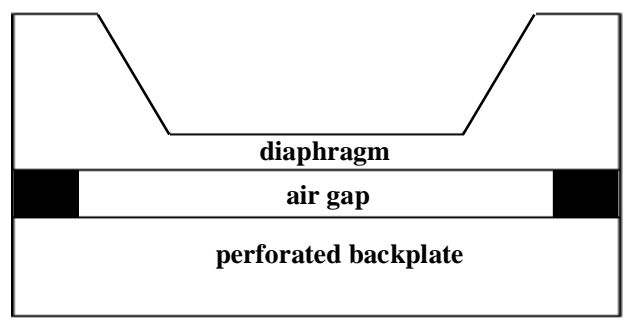

Figure 2. Structural model for capacitive microphone. 
Table 2. Design parameters for the required capacitive microphone.

\begin{tabular}{|l|l|}
\hline \multicolumn{1}{|c|}{ Parameter } & \multicolumn{1}{c|}{ Value } \\
\hline Diaphragm thickness & $1.00 \mu \mathrm{m}$ \\
\hline Diaphragm side length & $600 \mu \mathrm{m}, 700 \mu \mathrm{m}, 800 \mu \mathrm{m}, 900 \mu \mathrm{m}, 1000 \mu \mathrm{m}$ \\
\hline Air gap & $8 \mu \mathrm{m}$ \\
\hline Vent hole radius & $5 \mathrm{~mm}$ \\
\hline
\end{tabular}

\section{SIMULATION AND ANALYSIS}

\subsection{Simulation setting}

The Comsol Multiphysics ver.5.3 simulation software was used in this research to design and simulate the mechanical performance of MEMS capacitive microphone. Meanwhile, the finite element method (FEM) was used to solve the implemented model design by resolving differential equation that are formulated in mesh structure step [36]. The design parameters (Table 2) was used to build the geometry and simulation output created by meshing process. The novelty of $\mathrm{SiC}$ with its respected electrical and mechanical properties is used to simulate the movable diaphragm, which was never been reported before. The separation between the top plate $(\mathrm{SiC})$ and bottom plate $(\mathrm{Si})$ is set to be $8 \mu \mathrm{m}$, varied at applied pressure range between $-26 \mathrm{~dB}$ to $0 \mathrm{~dB}$ as the device used to detect gas at ultrasonic range.

\subsection{Resonant frequency}

Initially, the simulation has been focused on the resonant frequency of $36 \mathrm{kHz}$ by varying the size of the diaphragm. Six modes of resonant frequencies were computed with difference diaphragm's deflection. First mode deflection is considered as resonant frequency as the deflection of the diaphragm occur at the center as shown in Figure 3 . The comparison between side length and resonant frequency are summarized in Figure 4. Square diaphragm with five difference sizes are computed and it is observed that the larger diaphragm's size give the lowest resonant frequency. The diaphragm with side length of $1000 \mu \mathrm{m}$ is shown to have the lowest resonant frequency and this resonant frequency value increased by decreasing diaphragm's size. Therefore, we concluded that the simulation result presented by Figure 4 indicated that the resonant frequency of the diaphragm affected by the diaphragm's size.

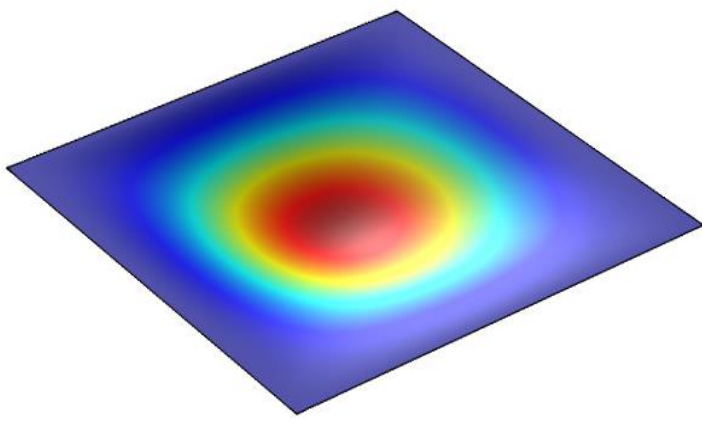

Figure 3. First mode of resonant frequency for $1000 \times 1000 \mu \mathrm{m}^{2}$ diaphragm.

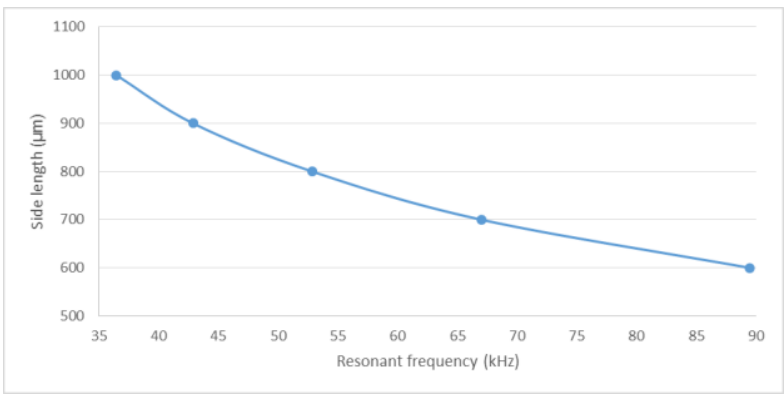

Figure 4. Resonant frequency at difference diaphragm's side length. 


\subsection{Deflection versus applied pressure}

Figure 5 represent the center deflection of the diaphragm at a series of external pressure load. Approximately, the applied pressure on the surface of the diaphragm is between $-26 \mathrm{~dB}$ to $0 \mathrm{~dB}$. It is observed that the center maximum deflection increases with the increase of applied pressure. Comparing the simulation result between the diaphragm's size and deflection, the deflection of wide diaphragm is less than the deflection by small diaphragm. Deflection of the diaphragm's side length of $1000 \mu \mathrm{m}, 900 \mu \mathrm{m}, 800 \mu \mathrm{m}$ and $700 \mu \mathrm{m}$ increase in order with applied pressure and achieved the maximum deflection at $700 \mu \mathrm{m}$ diaphragm. The diaphragm start to decrease its deflection at $600 \mu \mathrm{m}$ diaphragm for the same applied pressure. It is revealed that the limitation of diaphragm's deflection greatly depends on the size of diaphragm.

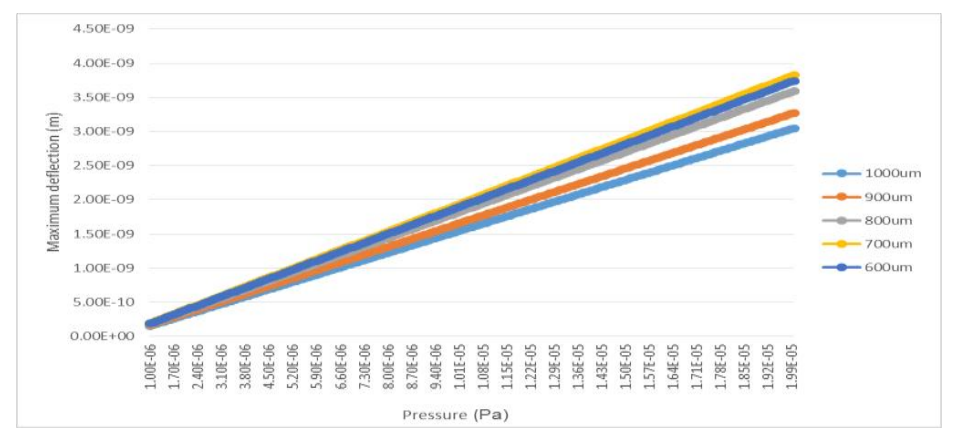

Figure 5. Deflection-pressure at various diaphragm's size.

The effect of the diaphragm's size on the von Mises stress is studied. The simulation of center deflection and stress analysis for the $1000 \times 1000 \mu^{2}$ diaphragm are shown in Figure 6 and Figure 7 respectively. The central maximum deflection of the diaphragm is $3.05 \mu \mathrm{m}$ and the maximum stress at $1.52 \mathrm{~N} / \mathrm{m}^{2}$. The default applied pressure for these analysis is $2.6 \mu \mathrm{Pa}$ as the diaphragm's deformation is half from the air gap between the plates for all the diaphragm's size as shown in Figure 8.

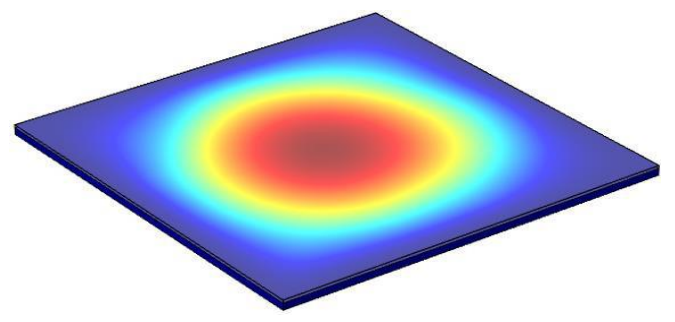

Figure 6. Deflection analysis of $1000 \times 1000 \mu \mathrm{m}^{2}$

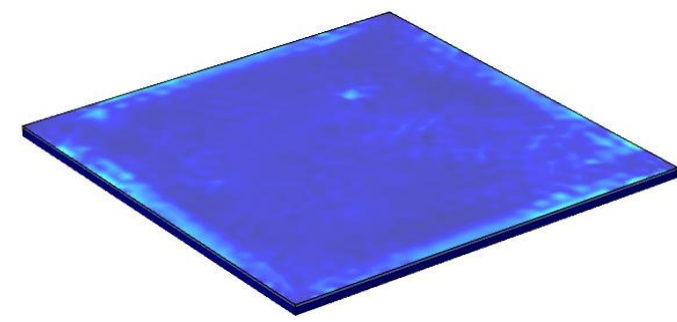

Figure 7. Von Mises stress analysis of $1000 \times 1000 \mu \mathrm{m}^{2}$

Figure 8. Touch-mode deflection

\section{CONCLUSION}

The MEMS capacitive microphone is designed through iterative simulation to study the mechanical performance such as maximum deflection, stress and resonant frequency of the device. Diaphragm with size of $1000 \mathrm{x} 1000 \mu^{2}$ employing $\mathrm{SiC}$ thin film as a sensing diaphragm gives great mechanical performance for ultrasonic range detection at harsh environment. The damping effect and electrical performance of the proposed device will study in future work. 


\section{REFERENCES}

[1] Y. Ning, A. Mitchell, and R. Tait, "Fabrication of a silicon micromachined capacitive microphone using a dryetch process," Sensors Actuators A Phys., 53, 237-242, (1996).

[2] J. Chen, L. Liu, Z. Li, Z. Tan, Y. Xu, and J. Ma, "On the single-chip condenser miniature microphone using DRIE and backside etching techniques," Sensors Actuators, A Phys., 103, 42-47, (2003).

[3] P. C.-P. Chao, C.-Y. Tsai, C.-W. Chiu, C.-H. Tsai, and T.-Y. Tu, "A new hybrid fabrication process for a high sensitivity MEMS microphone," Microsyst. Technol., 19, 1425-1431, (2013).

[4] D. T. Martin, J. Liu, K. Kadirvel, R. M. Fox, M. Sheplak, and T. Nishida, "A micromachined dual-backplate capacitive microphone for aeroacoustic measurements," J. Microelectromechanical Syst., 16, 1289-1302, (2007).

[5] U. Klein, K. Rasmussen, P. Rombach, and M. Mu, "The first low voltage , low noise differential silicon microphone, technology development and measurement results," 95, 196-201, (2002).

[6] J. Bergqvist and F. Rudolf, "A silicon condenser microphone using bond and etch-back technology," Sensors Actuators A. Phys., 45(2), 115-124, (1994).

[7] J. Bay, O. Hansen, and S. Bouwstra, "Design of a silicon microphone with differential read-out of a sealed double parallel-plate capacitor," Sensors and Actuators a-Physical, 53, 232-236, (1996).

[8] J. Bay, O. Hansen, and S. Bouwstra, "Micromachined double backplate differential capacitive microphone," $J$. Micromechanics Microengineering, 9 (1), 30-33, (1999).

[9] P. R. Scheeper, A. G. H. Van Der Donk, W. Olthuis, and P. Bergveld, "Fabrication of Silicon Condenser Microphones Using Single Wafer Technology,” J. Microelectromechanical Syst., 1(3), 147-154, (1992).

[10] A. S. Sezen, S. Sivaramakrishnan, S. Hur, R. Rajamani, W. Robbins, and B. J. Nelson, "Passive Wireless MEMS Microphones for Biomedical Applications," J. Biomech. Eng., 127(6), 1030-1034, (2005).

[11] Bandana, L. and Selvakumar, V. S., "Design and Simulation of Novel MEMS based Capacitive Microphone," IJSR, 2319-7064 (2016).

[12] K. Shin, J. Jeon, J. E. West, and W. Moon, "A micro-machined microphone based on a combination of electret and field-effect transistor," Sensors (Switzerland), 15(8), 20232-20249, (2015).

[13] A. Torkkeli, O. Rusanen, J. Saarilahti, H. Sepp, H. Sipola, and J. Hietanen, "Capacitive microphone with lowstress polysilicon membrane and high-stress polysilicon backplate," Sensors Actuators, A Phys., 85(1), 116-123, (2000).

[14] B. A. Ganji and B. Y. Majlis, "Slotted capacitive microphone with sputtered aluminum diaphragm and photoresist sacrificial layer," Microsyst. Technol., 16(10), 1803-1809, (2010).

[15] R. Schellin, G. Hess, W. Kuhnel, C. Thielemann, D. Trost, J. Wacker, and R. Steinmann, "Measurements of the mechanical behaviour of micromachined silicon and silicon-nitride membranes for microphones, pressure sensors and gas flow meters," Sensors Actuators A. Phys., 41, 287-292, (1994).

[16] R. Kressmann, M. Klaiber, and G. Hess, "Silicon condenser microphones with corrugated silicon oxide/nitride electret membranes," Sensors Actuators, A Phys., 100, 301-309, (2002).

[17] S. T. Hansen, a. S. Ergun, and B. T. Khuri-Yakub, "Acoustic sensing using radio frequency detection and capacitive micromachined ultrasonic transducers," 2001 IEEE MTT-S Int. Microw. Sympsoium Dig., 3, 22432246, (2001).

[18] J. S. Lee, Y.-G. Kim, S. Q. Lee, J. Lee, W. S. Yang, J. H. Jeon, and S.-G. Lee, "TiN/PECVD-Si3N4/TiN diaphragm-based capacitive-type MEMS acoustic sensor," Electron. Lett., 52(6), 468-470, (2016).

[19] Y. Iguchi, M. Goto, M. Iwaki, A. Ando, K. Tanioka, T. Tajima, F. Takeshi, S. Matsunaga, and Y. Yasuno, "Silicon microphone with wide frequency range and high linearity," Sensors Actuators, A Phys., 135(2), 420425, (2007).

[20] M. Charanjeet kaur, R. Pratap, and N. Bhat, "Design of a high sensitivity FET integrated MEMS microphone," Procedia Chem., 1(1), 875-878, (2009).

[21] T. Tajima, T. Nishiguchi, S. Chiba, A. Morita, M. Abe, K. Tanioka, N. Saito, and M. Esashi, "High-performance ultra-small single crystalline silicon microphone of an integrated structure," Microelectron. Eng., 508-519, (2003).

[22] T. Kasai, S. Sato, S. Conti, I. Padovani, F. David, Y. Uchida, T. Takahashi, and H. Nishio, "Novel concept for a MEMS microphone with dual channels for an ultrawide dynamic range," Proc. IEEE Int. Conf. Micro Electro Mech. Syst., 605-608, (2011).

[23] M. L. Kuntzman, D. Kim, and N. A. Hall, "Microfabrication and experimental evaluation of a rotational 
capacitive micromachined ultrasonic transducer," J. Microelectromechanical Syst., 24(2), 404-413, (2015).

H. Gharaei and J. Koohsorkhi, "Design and characterization of high sensitive MEMS capacitive microphone with fungous coupled diaphragm structure," Microsyst. Technol., 22(2), 401-411, (2016).

[25] B. A. Ganji and B. Y. Majlis, "High sensitivity and small size MEMS capacitive microphone using a novel slotted diaphragm," Microsyst. Technol., 15(9), 1401-1406, (2009).

[26] B. A. Ganji, "Design and Fabrication of a Novel MEMS Silicon Microphone," 313-328, (2011).

[27] C.-H. Huang, C.-H. Lee, T.-M. Hsieh, L.-C. Tsao, S. Wu, J.-C. Liou, M.-Y. Wang, L.-C. Chen, M.-C. Yip, and W. Fang, "Implementation of the CMOS MEMS Condenser Microphone with Corrugated Metal Diaphragm and Silicon Back-Plate," Sensors, 11(12), 6257-6269, (2011).

[28] M. Pedersen, W. Olthuis, and P. Bergveld, "High Performance Condenser Microphone with Fully Integrated CMOS Amplifier and DC-DC Voltage Converter," J. Microelectromechanical Syst., 7(4), 387-394, (1998).

[29] R. Paper and P. R. Scheepera, "A review of silicon microphones," 44, (1994).

[30] N. Marsi, B. Y. Majlis, A. A. Hamzah, and F. Mohd-Yasin, "High reliability of MEMS packaged capacitive pressure sensor employing 3C-SiC for high temperature," Energy Procedia, 68, 471-479, (2015).

[31] N. Marsi, B. Y. Majlis, A. A. Hamzah and M. Y. Faisal,“Comparison of Mechanical Deflection and Maximum Stress of 3C SiC- and Si-Based Pressure Sensor Diaphragms for Extreme Environment," (2012).

[32] N. Marsi, B. Y. Majlis, F. Mohd-Yasin, and A. A. Hamzah, "The fabrication of back etching 3C-SiC-on-Si diaphragm employing KOH + IPA in MEMS capacitive pressure sensor," Microsyst. Technol., 21(8), 16511661, (2014).

[33] Elwenspoek M, and Wiegerink R., [Mechanical Microsensors], Berlin Heidelberg: Springer-Verlag, Netherlands (2001).

[34] J. Yunas, J. Johari, A. A. Hamzah, Mimiwaty, I. C. Gebeshuber and B. Y. Majlis, "Design and fabrication of MEMS micropumps using double sided etching," J. Microelectron. Electron. Packag., 7(1), (2010).

[35] Z. Linlin, X. Chen, and S. Guangdi, "Analysis for load limitation of square-shaped silicon diaphragms," Solid. State. Electron., 50, 1579-1583, (2006).

[36] C. Maj, W. Zabierowski, and A. Napieralski, "Parametrized model of MEMS microphone in comsol multiphysics,” 2017 14th Int. Conf. Exp. Des. Appl. CAD Syst. Microelectron., 428-431, (2017). 